\title{
Effect of Drum's Excitation Frequency on Ride Comfort of a Single -Drum Vibratory Roller
}

\author{
Le Van Quynh, Nguyen Thanh Cong, Nguyen T. K. Thoa
}

\begin{abstract}
This study proposes a half-vehicle ride dynamic model of a single-drum vibratory roller interacting with the under the ground surface deformation to analyze the effects of drum's excitation frequency on vehicle ride. The excitation frequencies for a dynamic drum affect not only soil compression efficiency, but also vehicle ride comfort. In order to evaluate the effect on vehicle ride comfort, the weighted r.m.s acceleration responses of the vertical driver's seat and pitch angle of the cab according to the ISO 2631:1997(E) standard are chosen as objective functions. The excitation frequencies for a dynamic drum are respectively analyzed based on objective functions. The results show that the effects of drum's excitation frequency on vehicle ride are very obvious especially at the range of the low excitation frequency values for a dynamic drum. The results of this are the theoretical basis for designing the dynamic systems of a single-drum vibratory roller.
\end{abstract}

Index Terms - vibratory roller, drum, excitation frequency, dynamic model, ride vibration

\section{INTRODUCTION}

There have been many researches on the effect of design parameters of drum's isolation system and cab's isolation system cushions on vehicle ride comfort. The design parameters of the drum's isolation system were analyzed by a tandem vibratory roller dynamic model with 7 degrees of freedom (DOF) with different operations of the vehicleto see its effects on vehicle ride comfort[1]. By using a 12 -DOF in-plane ride dynamic model of a single-drum compactor, the design parameters of both drum's isolation system and cab's isolation system were investigated to find the influences of different design parameters on the whole body vibration responses [2]. The different design parameters of cab's isolation system were examined for its effects on vehicle ride comfort by using a 3-D nonlinear dynamic model of a single drum vibratory roller[3] and comparing with experimental results[18]. Three types of cab's isolation systems such as the traditional rubber, the hydraulic and pneumatic isolation systems were analyzed and compared to investigate its effectiveness on vehicle ride comfort using a 3-D nonlinear dynamic model of the off-road vibratory roller[4]. To improve vehicle ride comfort, the design parameters of drum's isolation systems of a double-drum vibrating roller were analyzed and optimized by using a genetic algorithm[5],

Le Van Quynh, Faculty of Automotive and Power Machinery Engineering, Thai Nguyen University of Technology, Thai Nguyen, Vietnam

Nguyen Thanh Cong, Faculty of Automotive and Power Machinery Engineering, Thai Nguyen University of Technology, Thai Nguyen, Vietnam Nguyen T. K. Thoa, Faculty of Automotive and Power Machinery Engineering, Thai Nguyen University of Technology, Thai Nguyen, Vietnam those of cab's isolation system of a single-drum vibrating roller were done by using a multi-objective genetic algorithm (GA)[6]. In order to reduce the cab's low-frequency shaking while vehicle operates under the different conditions, the design parameters of cab's main isolation system[7] and cab's auxiliary isolation system[8] were optimized by using the finite element method (FEM). The design parameters of cab's main isolation system were optimized by using FEM and GA[11]. The control methods for drum's isolation system and cab's isolation system such as the control strategy uses Fuzzy control[9] and a combined control method of Fuzzy and PID control[10] were proposed to improve the ride comfort of the vibratory rollers.

The effect of excitation frequencies of drum on the plastic deformation of soils was analyzed by Ario Kordestani[12], the influence of vibration frequency on the compaction of the deformation of soils was examined by C Wersäll [13]. On the other side, the influences of various kinds of soil ground on the driver's health and their working efficiency was figured out by Le V. Q, et al[14].

In this study, the excitation frequencies for a dynamic drum of a single-drum vibratory roller are respectively analyzed to recognize its effect on vehicle ride comfort. A half-vehicle ride dynamic model is established under the ground surface deformation. The weighted r.m.s acceleration responses of the vertical driver's seat and pitch angle of the cab according to the ISO 2631:1997(E) standard[16] are chosen as the objective functions. Matlab/Simulink software is used to simulate the vehicle dynamic model and calculate the values of the objective function.

\section{VEHICLE DYNAMIC MODEL}

\section{A. Half-vehicle ride dynamic model}

To analyze the effect of the excitation frequencies for a dynamic drum of a single -drum vibratory roller on the values of the objective functions according to the ISO 2631:1997(E) standard, a half-vehicle ride dynamic model is established under the ground surface deformation, as shown in Fig.1.

In Fig-1, $m_{d}, m_{f f}, m_{f}, m_{c}$ and $m_{s}$ are the mass of the dynamic drum, front vehicle body (frame), rear vehicle body, cab and driver's seat, respectively; $I_{f f}, I_{f r}$ and $I_{c}$ are the moment of inertia of the front vehicle body, and cab, respectively; $k_{s}$ and $c_{s}$ are the stiffness and damping of driver's seat suspension system; $k_{c f}$ and $c_{c r}$ are the stiffness and damping of the front and rear cab's isolation systems, respectively; $k_{t}$ and $c_{t}$ are the stiffness and damping of the tire; $k_{d}$ and $c_{d}$ are the stiffness and damping of the drum's isolation system, respectively; $z_{d}$, $z_{f f}, z_{f f}, z_{c}$ and $z_{s}$ are the vertical displacements at centre of gravity of the drum, the front vehicle body, the rear vehicle body, cab and driver's seat, respectively; $\varphi_{f f}, \varphi_{f r}$ and $\varphi_{c}$ are the 
pitch angle displacements of the front vehicle body and rear vehicle body and cab, respectively; $\mathrm{q}_{\mathrm{t}}$ and $\mathrm{q}_{\mathrm{d}}$ are the left and right excitation of road surface roughness at drum and tire, respectively; $l_{t}, l_{d}, l_{t l}, l_{t 2}, l_{c l}, l_{c l}, l_{c f}, l_{f r}, l_{s}$ are the distances; $F=F_{0} \sin (\omega t)$ is the force excitation of the vibrating drum; $\mathrm{F}_{0}$ is the amplitude of force excitation; $\omega$ is the angular frequency of the vibrator; $e$ is the eccentricity of the rotating mass; $F_{p}$ and $M_{p}$ are the coupling force in the vertical direction and the coupling moments in the front direction at the point of intersection, respectively; $v$ is the vehicle speed.

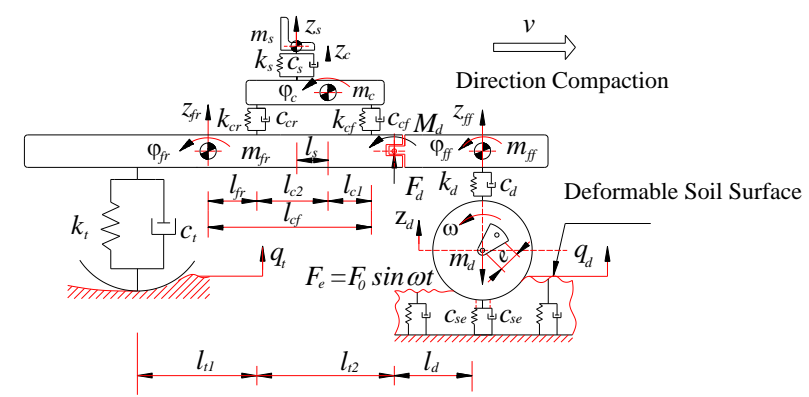

Figure 1. Half-vehicle ride dynamic model

\section{B. Equations of motion}

For the dynamic model showed in Fig-1, the multi-body system theory is used to separate the system into subsystems which are linked by the force and moment equations. D'Alembert's principle is used to set up force and moment equations to describe vehicle dynamic subsystems. The equations of motion can be written as

The equation of motion for seat vertical motion is written as follows

$$
m_{s} \ddot{z}_{s}=-\left[k_{s}\left(z_{s}-z_{c}+1_{s} \varphi_{c}\right)+c_{s}\left(\dot{z}_{s}-\dot{z}_{c}+1_{s} \dot{\varphi}_{c}\right] .\right.
$$

The equations of motion for the vertical and pitch motions of cab are written as follows

$$
\begin{aligned}
& m_{c} \ddot{z}_{c}=\left[k_{s}\left(z_{s}-z_{c}+l_{s} \varphi_{c}\right)+c_{s}\left(\dot{z}_{s}-\dot{z}_{c}+l_{s} \cdot \dot{\varphi}_{c}\right)\right] \\
& -\left[k_{c f}\left(z_{c}+l_{c 1} \varphi_{c}-z_{f r}-l_{f r} \varphi_{c}\right)+c_{c f}\left(\dot{z}_{c}+l_{c 1} \dot{\varphi}_{c}-\dot{z}_{f r}-l_{f r} \dot{\varphi}_{c}\right)\right] \\
& -\left[k_{c r}\left(z_{c}-l_{c 2} \varphi_{c}-z_{f r}-l_{c f} \varphi_{c}\right)+c_{c r}\left(\dot{z}_{c}-l_{c 2} \dot{\varphi}_{c}-\dot{z}_{f r}-l_{c f} \dot{\varphi}_{c}\right)\right]
\end{aligned}
$$

(2)

$$
\begin{aligned}
& I_{c} \varphi_{c}=-\left[k_{s}\left(z_{s}-z_{c}+l_{s} \varphi_{c}\right)+c_{s}\left(\dot{z}_{s}-\dot{z}_{c}+l_{s} \cdot \dot{\varphi}_{c}\right)\right] 1_{s} \\
& -\left[k_{c f}\left(z_{c}+l_{c 1} \varphi_{c}-z_{f r}-l_{f r} \varphi_{c}\right)+c_{c f}\left(\dot{z}_{c}+l_{c 1} \dot{\varphi}_{c}-\dot{z}_{f r}-l_{f r} \dot{\varphi}_{c}\right)\right] l_{c 1} \\
& +\left[k_{c r}\left(z_{c}-l_{c 2} \varphi_{c}-z_{f r}-l_{c f} \varphi_{c}\right)+c_{c r}\left(\dot{z}_{c}-l_{c 2} \dot{\varphi}_{c}-\dot{z}_{f r}-l_{c f} \dot{\varphi}_{c}\right)\right] l_{c 2}
\end{aligned}
$$

The coupling force in the vertical direction and the coupling moments in the front direction at the point of intersection are formulated as

$$
\begin{aligned}
& F_{d}=\left[k_{d}\left(\mathrm{z}_{f f}-\mathrm{z}_{d}\right)+c_{d}\left(\dot{\mathrm{z}}_{f f}-\dot{\mathrm{z}}_{d}\right] .\right. \\
& M_{d}=\left[k_{d}\left(\mathrm{z}_{f f}-\mathrm{z}_{d}\right)+c_{d}\left(\dot{\mathrm{z}}_{f f}-\dot{\mathrm{z}}_{d}\right] \mathrm{l}_{d} .\right.
\end{aligned}
$$

The equation of motion for the vertical and pitch motions of the rear vehicle body are written as follows

$$
\begin{aligned}
& m_{f r} \ddot{z}_{f r}=\left[k_{c f}\left(z_{c}+l_{c 1} \varphi_{c}-z_{f r}-l_{f r} \varphi_{c}\right)+c_{c f}\left(\dot{z}_{c}+l_{c 1} \dot{\varphi}_{c}-\dot{z}_{f r}-l_{f r} \dot{\varphi}_{c}\right)\right] \\
& +\left[k_{c r}\left(z_{c}-l_{c 2} \varphi_{c}-\mathrm{z}_{f r}-l_{c f} \varphi_{c}\right)+c_{c r}\left(\dot{z}_{c}-l_{c 2} \dot{\varphi}_{c}-\dot{\mathrm{z}}_{f r}-l_{c f} \dot{\varphi}_{c}\right)\right] \\
& -\left[k_{t}\left(z_{f r}-l_{t 2} \varphi_{f r}-\mathrm{q}_{t}\right)+c_{t}\left(\dot{z}_{f r}-l_{t 2} \dot{\varphi}_{f r}-\dot{\mathrm{q}}_{t}\right)\right]-\mathrm{F}_{d}
\end{aligned}
$$

$$
\begin{aligned}
& I_{f r} \ddot{z}_{f r}=\left[k_{c f}\left(z_{c}+l_{c 1} \varphi_{c}-z_{f r}-l_{f r} \varphi_{c}\right)+c_{c f}\left(\dot{z}_{c}+l_{c 1} \dot{\varphi}_{c}-\dot{z}_{f r}-l_{f r} \dot{\varphi}_{c}\right)\right] 1_{f r} \\
& +\left[k_{c r}\left(z_{c}-l_{c 2} \varphi_{c}-\mathrm{z}_{f r}-l_{c f} \varphi_{c}\right)+c_{c r}\left(\dot{z}_{c}-l_{c 2} \dot{\varphi}_{c}-\dot{z}_{f r}-l_{c f} \dot{\varphi}_{c}\right)\right] 1_{c f} \\
& -\left[k_{t}\left(z_{f r}-l_{t 2} \varphi_{f r}-\mathbf{q}_{t}\right)+c_{t}\left(\dot{z}_{f r}-l_{t 2} \dot{\varphi}_{f r}-\dot{\mathrm{q}}_{t}\right)\right] \mathrm{l}_{t 2}-\mathrm{F}_{d} l_{t 1}-M_{d}
\end{aligned}
$$

(7)

The equation of motion for the dynamic drum is written as follows

$$
m_{d} \ddot{z}_{d}=m_{e} e(2 \pi f)^{2} \sin 2 \pi f t+F_{d}-k_{s e} z_{d}-c_{s e} \dot{z}_{d}
$$

III. VEHICLE RIDE COMFORT CRITERIA[1],[3],[15]

A number of methods can be applied to evaluate the vehicle ride comfort, for examples, frequency-domain and time-domain methods.

$$
a_{w}=\left[1 / T \int_{0}^{T} a_{w}{ }^{2}(t) d t\right]^{1 / 2}
$$

In this formula, $a_{w}(t)$ is the weighted acceleration (translational and rotational) as a function of time, $\mathrm{m} / \mathrm{s}^{2} ; \mathrm{T}$ is the duration of the measurement, s.

For indications of likely reactions to various magnitudes of overall vibration in the public transport and vehicle, a synthetic index-called weighted r.m.s acceleration, aw can be calculated from formula Eq.(9); besides, the r.m.s. value of the acceleration in vehicle would be compared with the values in Table1.

Table 1. Comfort levels related to $a_{w}$ threshold values[16]

\begin{tabular}{|l|l|}
\hline $\mathbf{a}_{\mathbf{w}} /\left(\mathbf{m . s} \mathbf{s}^{\mathbf{2}}\right)$ & Comfort level \\
\hline$<0.315$ & Not uncomfortable \\
\hline $0.315 \div 0.63$ & A little uncomfortable \\
\hline $0.5 \div 1.0$ & Fairly uncomfortable \\
\hline $0.8 \div 1.6$ & Uncomfortable \\
\hline $1.25 \div 2.5$ & Very uncomfortable \\
\hline$>2$ & Extremely uncomfortable \\
\hline
\end{tabular}

\section{SIMULATION AND DISCUSSION}

In order to criticise the effect of the excitation frequencies for a dynamic drum on vehicle ride comfort, Matlab/simulink software is applied to solve the differential equations in Part II with a set of simulation parameters of a single -drum vibratory roller[11] when vehicle compacts under two cases including the compacts on original place (Case 1), and compacts and moves on the elastic soil ground and rear wheel moves on the road surface conditions as ISO level E according to the International Standards Organization (ISO) 8608 [17] at the speed of $\mathrm{v}=3 \mathrm{~km} / \mathrm{h}$ (Case 2).

The acceleration responses of the vertical driver's seat and pitch angle of the cab when vehicle compacts in Case 1 and Case 2 at low and high excitation frequencies for a drum $(\mathrm{f}=30 \mathrm{~Hz}$ and $\mathrm{f}=35 \mathrm{~Hz})$ are shown Fig. 2 and Fig.3.

From the results of Fig.2a, we can determine the values of the weighted rms acceleration of the vertical driver's seat $\left(\mathrm{a}_{\mathrm{ws}}\right)$ in Case 1 at low and high excitation frequencies for a $\operatorname{drum}\left(\mathrm{F}_{0}=0.28 \times 10^{6} \mathrm{~N}, \mathrm{f}=30 \mathrm{~Hz}\right.$ and $\left.\mathrm{F}_{0}=0.19 \times 10^{6} \mathrm{~N}, \mathrm{f}=35 \mathrm{~Hz}\right)$ are $0.3492 \mathrm{~m} / \mathrm{s}^{2}$ and $0.6418 \mathrm{~m} / \mathrm{s}^{2}$. The $\mathrm{a}_{\mathrm{ws}}$ value at the high excitation frequency for a drum $\mathrm{F}_{0}=0.19 \times 10^{6} \mathrm{~N}$ and $\mathrm{f}=35 \mathrm{~Hz}$ reduce by $83.79 \%$ in comparison with at the low excitation frequency for a drum $\mathrm{F}_{0}=0.28 \times 10^{6} \mathrm{~N}, \mathrm{f}=30 \mathrm{~Hz}$. Those values of $\mathrm{a}_{\mathrm{ws}}$ are the uncomfortable conditions for driver comfort (according to Tab.1). Vehicle's ride comfort is improved significantly when the vehicle compacts in Case 1 at the excitation high frequency for a drum. 


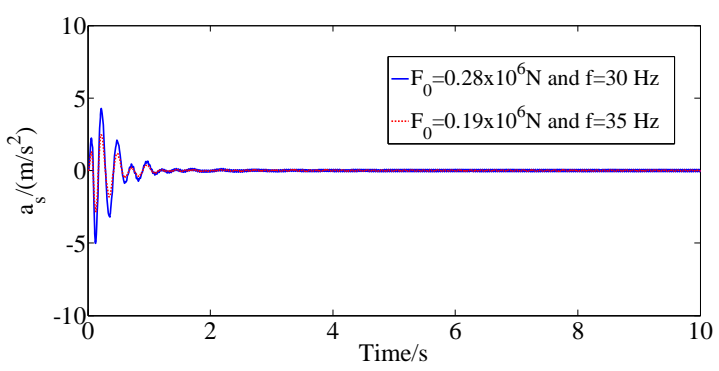

(a) Vertical driver's seat

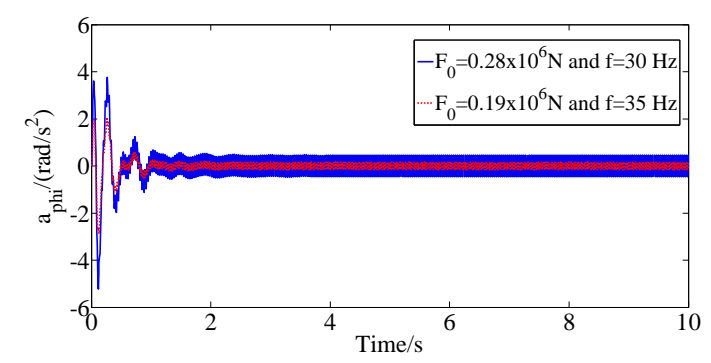

(b) Pitch angle of the cab

Figure2. The acceleration responses in Case 1

From the results of Fig.2b, we can determine the values of the weighted $\mathrm{rms}$ acceleration of pitch angle of cab $\left(\mathrm{a}_{\mathrm{wphi}}\right)$ in Case 1 at low and high excitation frequencies for a drum $\left(\mathrm{F}_{0}=0.28 \times 10^{6} \mathrm{~N}, \mathrm{f}=30 \mathrm{~Hz}\right.$ and $\left.\mathrm{F}_{0}=0.19 \times 10^{6} \mathrm{~N}, \mathrm{f}=35 \mathrm{~Hz}\right)$ are $0.3535 \mathrm{rad} / \mathrm{s}^{2}$ and $0.6742 \mathrm{rad} / \mathrm{s}^{2}$. The $\mathrm{a}_{\mathrm{wphi}}$ value at the excitation high frequency for a drum $\mathrm{F}_{0}=0.19 \times 10^{6} \mathrm{~N}$ and $\mathrm{f}=35 \mathrm{~Hz}$ reduce by $90.72 \%$ in comparison with at the excitation low frequency for a drum $F_{0}=0.28 \times 10^{6} \mathrm{~N}$, $\mathrm{f}=30 \mathrm{~Hz}$. Cab's pitch angle of cab significantly is reduce by the excitation high frequency for a drum.

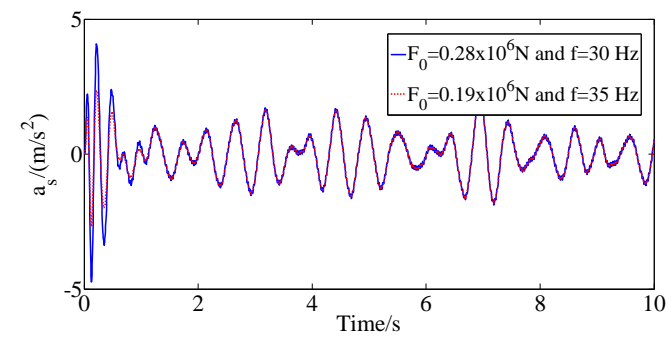

(a) Vertical driver's seat

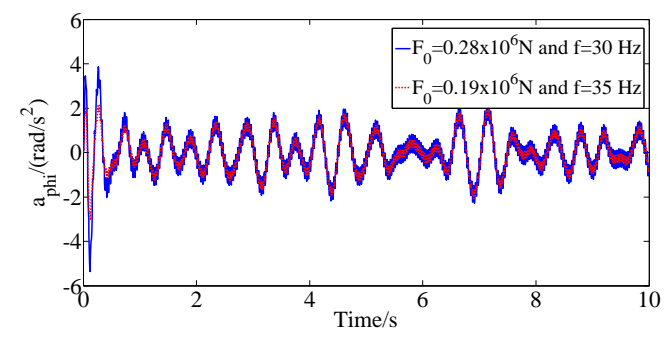

(b) Pitch angle of the cab

Figure 3. The acceleration responses in Case 2

From the results of Fig.3a, we can obtain the values of the weighted rms acceleration of the vertical driver's seat $\left(\mathrm{a}_{\mathrm{ws}}\right)$ in Case 2 at low and high excitation frequencies for a drum $\left(\mathrm{F}_{0}=0.28 \times 10^{6} \mathrm{~N}, \mathrm{f}=30 \mathrm{~Hz}\right.$ and $\left.\mathrm{F}_{0}=0.19 \times 10^{6} \mathrm{~N}, \mathrm{f}=35 \mathrm{~Hz}\right)$ are $0.8013 \mathrm{~m} / \mathrm{s}^{2}$ and $0.9393 \mathrm{~m} / \mathrm{s}^{2}$. The $a_{w s}$ value at the high excitation frequency for a drum $\mathrm{F}_{0}=0.19 \times 10^{6} \mathrm{~N}$ and $\mathrm{f}=35 \mathrm{~Hz}$ reduce by $17.22 \%$ in comparison with at the low excitation frequency for a drum $\mathrm{F}_{0}=0.28 \times 10^{6} \mathrm{~N}, \mathrm{f}=30 \mathrm{~Hz}$. Those values of $\mathrm{a}_{\mathrm{ws}}$ are the uncomfortable conditions for driver comfort (according to Tab.1). Similarly, from the results of Fig.3b, it also indicates that the $\mathrm{a}_{\mathrm{wphi}}$ value at the high excitation frequency for a drum $\mathrm{F}_{0}=0.19 \times 10^{6} \mathrm{~N}$ and $\mathrm{f}=35 \mathrm{~Hz}$ reduce by $17.32 \%$ in comparison with at the low excitation frequency for a drum $\mathrm{F}_{0}=0.28 \times 10^{6} \mathrm{~N}, \mathrm{f}=30 \mathrm{~Hz}$.

In order to evaluate the effect of the excitation frequencies for a dynamic drum on the $\mathrm{a}_{\mathrm{ws}}$ and $\mathrm{a}_{\mathrm{wphi}}$ values, the excitation frequencies for a dynamic drum $\mathrm{f}=[15,20,25,30,35,40,45$, 50] are selected for evaluation. The $\mathrm{a}_{\mathrm{ws}}$ and $\mathrm{a}_{\mathrm{wphi}}$ values with the different excitation frequencies for a dynamic drum in Case 1 and Case 2 are shown in Fig. 4 and Fig.5.

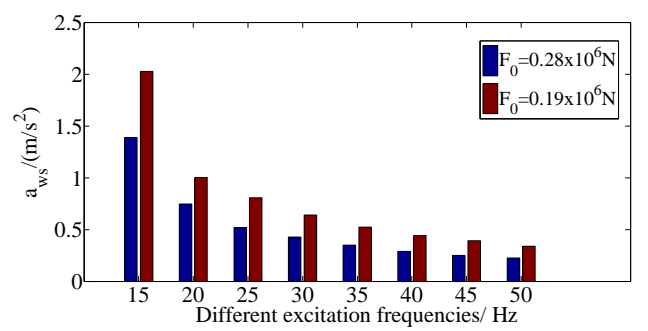

(a) Vertical driver's seat

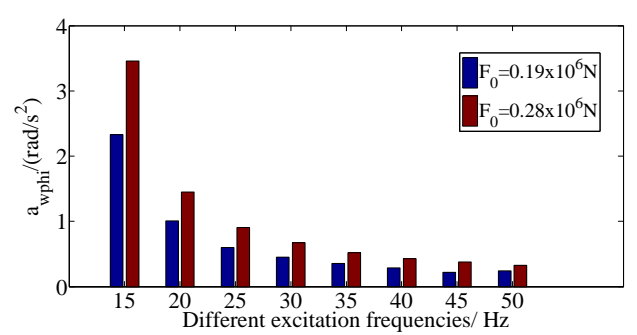

(b) Pitch angle of the cab

Figure 4. $a_{w s}$ and $a_{w p h i}$ values with the different excitation frequencies for a dynamic drum in Case 1

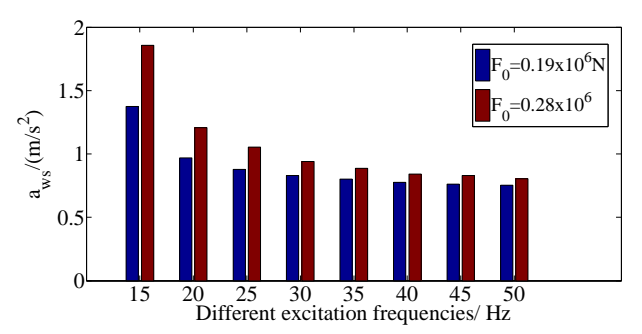

(a) Vertical driver's seat

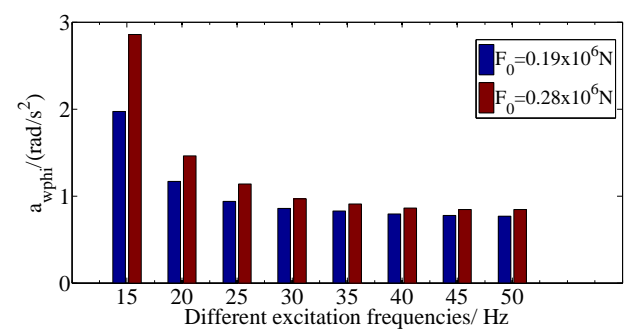

(b) Pitch angle of the cab

Figure 5. $a_{w s}$ and $a_{w p h i}$ values with the different excitation frequencies for a dynamic drum in Case 2

From the results of Fig. 4 with Case 1, it is pointed out that the $f$ value increases, the $a_{w s}$ and $a_{w p h i}$ values with the amplitude of excitation force for a drun $\mathrm{F}_{0}=0.28 \times 10^{6} \mathrm{~N}$ reduce by $35.17 \%, 24.75 \%, 20.27 \%, 13.24 \%, 10.55 \%, 8.7 \%, 9.14 \%$, $6.73 \%$ and $44.98 \%, 25.49 \%, 21.40 \%, 13.26 \%, 10.05 \%$, $8.09 \%, 8.82 \%, 9.77 \%$ respectively in comparison with the amplitude of excitation force for a drun $F_{0}=0.28 \times 10^{6} \mathrm{~N}$. The $\mathrm{a}_{\mathrm{ws}}$ and $\mathrm{a}_{\mathrm{wphi}}$ values significantly reduce at the range of the low excitation frequency values. Similarly, from the results of Fig.5 with Case 2, the $\mathrm{a}_{\mathrm{ws}}$ and $\mathrm{a}_{\mathrm{wphi}}$ values are indicated to 
reduce significantly at the range of the low excitation frequency values. The effect of the excitation frequencies for a dynamic drum can be seen obviously.

\section{CONCLUSION}

In this study, a half-vehicle ride dynamic model under the ground surface deformation is established for analyzing and evaluating the effects of drum's excitation frequency on vehicle ride. The major conclusions can be drawn from the analysis results as follows:

i) The $a_{w s}$ value with Case 1 at the high excitation frequency for a drum $\mathrm{F}_{0}=0.19 \times 10^{6} \mathrm{~N}$ and $\mathrm{f}=35 \mathrm{~Hz}$ reduce by $83.79 \%$ in comparison with at the low excitation frequency for a drum $\mathrm{F}_{0}=0.28 \times 10^{6} \mathrm{~N}, \mathrm{f}=30 \mathrm{~Hz}$ and the $\mathrm{a}_{\text {wphi }}$ value reduce by $90.72 \%$ in comparison with at the excitation low frequency for a drum $\mathrm{F}_{0}=0.28 \times 10^{6} \mathrm{~N}, \mathrm{f}=30 \mathrm{~Hz}$.

ii) The $a_{w s}$ value with Case 2 at the high excitation frequency for a drum $\mathrm{F}_{0}=0.19 \times 10^{6} \mathrm{~N}$ and $\mathrm{f}=35 \mathrm{~Hz}$ reduce by $17.22 \%$ in comparison with at the low excitation frequency for a drum $\mathrm{F}_{0}=0.28 \times 10^{6} \mathrm{~N}, \mathrm{f}=30 \mathrm{~Hz}$ and the $\mathrm{a}_{\text {wphi }}$ value reduce by $17.32 \%$ in comparison with at the low excitation frequency for a drum $\mathrm{F}_{0}=0.28 \times 10^{6} \mathrm{~N}, \mathrm{f}=30 \mathrm{~Hz}$.

iii) The $a_{w s}$ and $a_{w p h}$ values with Case1 and Case 2 significantly reduce at the range of the low excitation frequency values. The effect of the excitation frequencies for a dynamic drum is very obvious.

\section{ACKNOWLEDGMENT}

This research was supported financially by Thai Nguyen University of Technology, TNUT, Viet Nam.

\section{REFERENCES}

[1] Le Van Quynh, Thao V. T. P., et al, "Study on influence of design parameters of drum's metal rubber isolation system of double vibratory roller on ride comfort," International Research Journal of Engineering and Technology (IRJET), Vol. 6, Issue 6, 2019, p. 1647-1651.

[2] Kordestani Rakheja, et al, "Analysis of ride vibration environment of soil compactors," SAE International Journal of Commercial Vehicles, Vol. 3, Issue 1, 2010, p. 259-272.

[3] Le Van Quynh, Thao V. T. P., et al, "Influence of design parameters of cab's isolation system on vibratory roller ride comfort under the deformed ground surfaces," International Research Journal of Engineering and Technology (IRJET), Vol. 6, Issue 6, 2019, p. 1974-1978.

[4] Liem N. V., Run Z. J., et al, "Vibration analysis and modeling of an off-road vibratory roller equipped with three different cab's isolation mounts," Shock and Vibration, Vol. 2018, 2018, p. 8527574.

[5] LV Quynh, VTP Thao, TT Phong, "Optimal design parameters of drum's isolation system for a double-drum vibratory roller", Vibroengineering PROCEDIA, Vol. 31, 2020, p. 74-79.

[6] Le V. Q., Nguyen K. T., "Optimal design parameters of cab's isolation system for vibratory roller using a multi-objective genetic algorithm," Applied Mechanics and Materials, Vol. 875, 2018, p. 105-112.

[7] LV Quynh, Z Jianrun,et al, "Experimental modal analysis and optimal design of cab's isolation system for a single drum vibratory roller," Vibroengineering PROCEDIA, Vol. 31, 2020, p. 52-56.

[8] Quynh L. V., Zhang J. R., et al, "Vibration analysis and optimal design for cab's isolation system of vibratory roller". Advanced Materials Research, Vol. 199, 200,2011, p. 936-940.

[9] Liu S. N., Yan S. R., et al, "Dynamic and control of vibratory road roller based on Magneto-Rheological semi-active damper," Advanced Materials Research, Vol. 479, Issue 481, 2012, p. 1200-1204.

[10] V Nguyen, R Jiao, V Le, A Hoang, "Performance of PID-Fuzzy control for cab isolation mounts of soil compactors," Mathematical Models in Engineering, Vol. 5, Issue 4, 2019, p. 137-145.

[11] Quynh Le Van, "Vibration Study and Control Cab of Vibratory Roller," Southeast University, Nanjing, China, 2013.

[12] Ario Kordestani, "Ride vibration and vompaction dynamics of vibratory soil vompactors," Master's thesis, Concordia University, Montreal, Quebec, Canada, 2010.
[13] Carl Wersäll, "Frequency Optimization of Vibratory Rollers and Plates for Compaction of Granular Soil," Doctoral Thesis, Royal Institute of Technology, Stockholm, 2016.

[14] Le V. Q., Zhang J. R., et al. Ride comfort evaluation of vibratory roller under different soil ground. Transactions of the Chinese Society of Agricultural Engineering, Vol. 29, 2013, p. 39-47.

[15] Long L. X., Quynh L. V., Cuong B. V., "Study on the influence of bus suspension parameters on ride comfort," Vibroengineering Procedia, Vol. 21, 2018, p. 77-82.

[16] ISO 2631-1 (1997). "Mechanical Vibration and Shock-Evaluation of Human Exposure to Whole-Body Vibration, Part I: General Requirements," The International Organization for Standardization, 1997.

[17] ISO 8068 (1995), "Mechanical Vibration-Road Surface Profiles-Reporting of Measured Data," International Organization for Standardization.

[18] Le V. (2017), "Ride Comfort Analysis of Vibratory Roller via Numerical Simulation and Experiment," DEStech Transactions on Engineering and Technology Research.

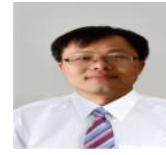

Le Van Quynh received his Ph.D. degree in School of Mechanical Engineering, Southeast University, China in 2013. Now he is an Associate Professor at the Department of Automotive Engineering, Faculty of Automotive and Power Machinery Engineering, Thai Nguyen University of Technology, Viet Nam. His current research interests include Vehicle dynamics, Vehicle vibration and noise, Optimal design and control. 